\title{
Reforma do Aparelho do Estado: LIMITES DO GERENCIALISMO FRENTE AO PATRIMONIALISMO ${ }^{1}$
}

José Antonio Gomes de Pinho*

Introdução

Tomo tudo que fica velho e tem que ser reformado ou substituído, o mesmo acontece com o Estado no Brasil. A reforma do Estado assumiu na presente administração, governo Fernando Henrique Cardoso, uma importância estratégica, tendo sido colocada como pré-requisito para outras reformas. Na verdade, o que está acontecendo trata-se de uma reforma do aparelho do Estado, ou mais precisamente da administração do Executivo, do que uma reforma do Estado ampla, que, aliás, se faz necessária. Poderíamos dizer até que o sucesso e a viabilidade de uma reforma do aparelho administrativo do Executivo depende sobremaneira de uma reforma do Estado no sentido amplo. Para se conhecer que reforma de Estado, aqui entendido como reforma do aparelho administrativo do Executivo, queremos, temos que nos perguntar: reforma do Estado para que e para quem? Devemos ainda nos perguntar: reformar o quê? Ou seja, o que dá para reformar, o que é possível reformar?

Um ponto de partida necessário é entender que a reforma em curso não é a primeira empreendida pelo Estado brasileiro. Para entendermos a presente mudança torna-se necessário conhecer, ainda que de forma panorâmica, as reformas precedentes. Para tanto se faz neces. sário uma retrospectiva histórica, ainda que breve.

* Professor da Escola de Administração e do Núcleo de Pós-Graduação em Administração - (NPGA) da Universidade Federal da Bahia (UFBA). 


\section{As Reformas da Administração Pública no Brasil}

\section{A Revolução de 30 e a Reforma do Estado}

O governo provisório de Getúlio Vargas inicia em 1933 os estudos de reforma da administração pública (Martins: 1977) que viria a culminar com a criação do DASP (Departamento de Administração do Serviço Público) instituído em 1938 já no auto-chamado Estado Novo. Este fato revela que o DASP não é uma cria específica do Estado Novo, ou seja, do regime ditatorial mas teve como motivação exata de sua criação o momento revolucionário ou reformista inaugurado com o movimento de 30 . A criação do DASP tem sido apontada como a implantação de uma burocracia de tipo weberiana no Brasil. Weber finalmente chegaria ao Brasil através do DASP. A implantação de uma burocracia racional, moderna justificava-se dentro do espírito revolucionário de conduzir o País a um nível de desenvolvimento até então nunca empreendido. Esse novo nível passava pela admissão da necessidade da via industrializante como meio de construir um país condizente com o potencial de seus recursos e com a sua expressão espacial e baseava-se na constatação da incapacidade da burguesia nacional de um empreendimento desse fôlego. Assim restava o Estado para empreender ess` missão e este deveria aparelhar-se para tal tarefa. A implantação de uma burocracia moderna representava por outro lado o deslocamento de uma burocracia patrimonialista que dominava o Brasil compatível com suas estruturas políticas. Colocava-se um "desafio de criar uma administração pública moderna, burocrática, sintonizada com os novos tempos que se previa para o País, capaz, portanto, de desempenhar papéis relevantes na regulamentação econômica, no fomento ao crescimento industrial, no atendimento das crescentes demandas sociais e dos novos encargos impostos ao Estado pelo sistema produtivo nacional" (Nogueira: 1996: 9). Martins (1997) considera esta reforma como "ambiciosa" mas limitada por pressões populistas-clientelistas estabelecendo um "padrão duplo" onde os altos escalōes da burocracia seguiram esse padrão moderno enquanto os escalóes inferiores ficam sujeitos as manipulações populistas $e$ clientelistas. É importante ressaltar que essas características se mantêm ao longo das décadas seguintes em que pesem as mudanças de tipo de governo e que esse duplo padrão permanece até os dias de hoje (Martins, 1997). 
Assim, nosso primeiro passo é relativizar essa reforma weberiana ocorrida através do DASP. E é o próprio Martins (1997) que faz isto ao proclamar que a reforma intencionava formar dentro do aparelho estatal "algo parecido com uma burocracia weberiana", ou seja, ele está dizendo que não foi exatamente uma reforma weberiana mas "algo parecido". E em seguida arremata que esta reforma "foi parcialmente distorcida e, mais tarde, abandonada pela cultura política clientelista profundamente enraizada" (Martins: 1997: 19), ou seja, além de ter sido apenas uma reforma que se aproximou dos pressupostos weberianos ainda foi "distorcida" e "abandonada". Mais profundamente, prevaleceu a "cultura clientelista profundamente enraizada". Com a convivência do que poderíamos chamar um padrão quase-weberiano com o padrão historicamente assentado do padrão patrimonialista, Martins traça um paralelo com a geologia ao colocar que "os aparelhos e os quadros do Estado seguiram um padrão de crescimento por sedimentação de estruturas sobrepostas e diferentes - quase como camadas geológicas - com padrões decrescentes de eficácia e eficiência dos serviços públicos nas camadas inferiores ou mais antigas" (Martins: 1997: 19).

Vale a pena gastar algum espaço mais no sentido de discutir essa experiência do DASP no sentido de avaliar o quão weberiana ela foi para podermos, mais a frente, entender qual é a reforma verdadeira que se quer e tem que se fazer. Duas preocupações merecem ser ressaltadas. Primeiro, Nogueira também recorre à analogia geológica para explicar o que acontecia. "Disso resultou um Estado precocemente hipertrofiado e todo multifacetado, cujas diversas camadas constitutivas - superpostas por sedimentação passiva - acabaram por alimentar a formação de uma macrocefálica bifrontalidade" onde "duas avantajadas cabeças - uma racional-legal, outra patrimonialista - comunicam-se e interpenetram-se funcionalmente em clima de recíproca competição e hostilidade, impedindo a imposição categórica de uma sobre a outra" (Nogueira: 1996:9). Identifica-se uma "permeabilidade ao clientelismo, na sua congênita "resistência à mudança"” (Nogueira: 1996:9). Segundo, "o impulso reformador do DASP, porém, não chegou a se completar: dele não nasceu a administração pública moderna, ágil, eficiente e eficaz que se imaginava indispensável para o País", não conseguindo o reformismo daspiano sanear as contradições da administração estatal (Nogueira: 1996: 10). Assim é que dentro do mesmo Estado Novo que criou o DASP criou-se também um sem número de órgãos 
regulamentadores da produção econômica colocados à margem da estrutura administrativa convencional gerando uma máquina administrativa "quase esquizofrênica" (Nogueira: 1996:9). Em outras palavras, as mesmas mãos que queriam ser weberianas não conseguiam, ou não podiam resistir ao poder histórico do patrimonialismo. Construímos assim um híbrido administrativo onde convivem uma estrutura meio weberiana e a sólida estrutura patrimonialista ainda que esta se atualize, se transmute para ficar contemporânea. Evidentemente esse sistema exibe alto grau de promiscuidade com a interpenetração de uma esfera pela outra, onde a estrutura weberiana, ou já meio weberiana é contaminada e se deixa contaminar pela patrimonialista e esta até pode ter uma face, uma aparência weberiana.

Se, para os mais apressados, o sistema burocrático, ou pseudo-burocrático, era uma obra do Estado Novo e só existia por conta deste, "a queda da ditadura Vargas e a democratização do Brasil em 1945 não ajudaram muito a modernizar a administração pública como um todo" (Martins: 1997:18). Se, por um lado, a administração pública ficou mais transparente frente ao Congresso, de outro lado, os partidos políticos ampliavam suas práticas clientelistas "profundamente enraizadas" ao fazerem indicações dentro da "classe média baixa" e "estratos socialmente menos privilegiados" para cargos públicos (Martins: 1997: 18). Como no velho patrimonialismo, os cargos são para as pessoas, não as pessoas para os cargos (Faoro, 1979), ou seja, existem pessoas que precisam de cargos, então estes têm que ser criados para as pessoas. Este procedimento acaba ocorrendo em uma economia onde a velocidade de criação de empregos não acompanha as necessidades do crescimento demográfico (Martins, 1997) e numa economia centrada no Estado, que tem no Estado o seu fator impulsionador. Estas afirmações devem de algum modo ser qualificadas. Acreditamos que essas indicações não se restringem aos setores sociais mencionados, sendo mais amplas. Isto ocorreria de uma forma generalizada mas principalmente nas áreas geográficas onde a penetração e o desenvolvimento do capitalismo não fizeram emergir uma economia mais dinâmica. São essas áreas justamente onde o patrimonialismo se faz mais presente, vivo e atuante e onde, consequentemente, o Estado se torna objeto de desejo dos grupos patrimonialistas para viabilizar seus desejos e também moeda de troca para assegurar lealdades e apoios políticos. Nessas áreas pertencer ao Estado para grupos de maior posição social também é 
Reforma do Aparelho do Estado: Limites do Gerencialismo frente ao Patrimonialismo

uma questão de status. Evidentemente todos esses procedimentos vão conformando um Estado inchado, marcado por uma ineficiência de escala que, por ser assim, dificulta e conspira cada vez mais contra a penetração do capitalismo na economia e nas transformações políticas necessárias para vencer essa ordem.

\section{O Estado Paralelo na Democracia}

Este híbrido administrativo ainda foi mais exacerbado - já o havia sido no segundo governo Vargas - no período de governo de Juscelino Kubitschek (1956/61) onde a decisão de acelerar o crescimento econômico praticamente criou mecanismos paralelos de governo ficando a estrutura burocrática tradicional impregnada dos padrões rebaixados de eficiência. Esta situação resultava da conscientização de que a estrutura tradicional não poderia dar conta da política ambiciosa de crescer "cinquenta anos em cinco", que "o sistema administrativo vigente tornara-se precocemente obsoleto e não se ajustava mais à realidade econômica e social do País" (Nogueira: 1996: 12). Optou-se por não enfrentar o problema e reformar o sistema existente mas sim pela "construção de um novo sistema, ao lado do antigo, que foi, em certo sentido, congelado" (Nogueira: 1996: 12). quadro construído por Araújo (1977) , abaixo reproduzido, mostra a quantidade de empresas estatais implantadas no período do governo Kubitschek valendo observar que estas se somam às existentes. Esta opção tomada nesse período, normalmente tido como o mais democrático da vida brasileira, mostra como que a construção do Estado paralelo não é privilégio de regimes autoritários mas que na tradição brasileira esse também é o caminho dentro dos parâmetros da democracia. Isto está querendo indicar duas possibilidades: 1) a burocracia patrimonialista não havia sido suficientemente weberianizada para resultar numa estrutura burocrática, tida como um avanço em relação à patrimonialista e, assim, não dava conta da tarefa de aprofundamento do capitalismo; 2) a tradição autoritária e centralizadora brasileira conduzia à busca de caminhos alternativos fora das estruturas burocráticas assentadas, caminhos esses mais desimpedidos para as decisões e ações. O mais provável é que a realidade tenha sido uma combinação das duas possibilidades: nem éramos suficientemente weberianizados, guardando fortes traços de patrimonialismo e a tradi- 
ção autoritária brasileira se mostrou mais uma vez, ainda que em um regime democrático.

Uma outra perspectiva deve ser ainda adicionada. Ao que tudo indica nesse período de democracia (1946/64), mais amplo que apenas o governo $\mathrm{JK}$, não parece ter ocorrido um esforço consistente e assumido de fazer ou um aprofundamento das estruturas burocráticas ou uma correção do que houve de equivocado e distorcido nestas. Se esta hipótese se confirma chegamos à conclusão que o esquema burocrático imperou apenas durante a primeira fase do DASP, a do Estado Novo e logo em seguida se assiste ao seu descrédito e incapacidade de se afirmar. Quer dizer, não houve nem aprofundamento nem reforma, o que indicaria uma vitória da cultura patrimonialista da sociedade e do Estado brasileiros.

\section{A Reforma do Aparelho do Estado no (Novo) Regime Autoritário}

A reforma, ou tentativa de, do aparelho do Estado só vem a ocorrer efetivamente já no período do Estado Burocrático-Autoritário, em 1967, através do Decreto-lei n. 200, uma "ambiciosa reforma das estruturas do Estado e dos procedimentos burocráticos" (Martins: 1997: 21). Ao pretender "contornar a rigidez das estruturas da administração direta" e "introduzir o espírito gerencial privado na administração do setor paraestatal" os governos militares incentivaram a criação de mais empresas fora da administração direta que acabaram fugindo ao controle do governo (Martins: 1997: 22). O interessante quadro produzido por Araújo (1977) mostra a intensidade da ação produzida no período, superando fortemente aquela produzida no período do Estado Novo, início da intervenção mais sistemática e explícita do Estado na economia.

Os dados da tabela a seguir mostram como ocorre uma dramática construção de um estrutura estatal paralela no período do Estado Novo (porque estava saindo de duas para doze empresas), outra forte inserção no segundo governo Vargas, seguido de outra montagem de uma estrutura paralela significativa no governo JK e um crescimento exponencial do Estado paralelo no regime autoritário recente que supera a soma de todas as empresas estatais criadas em toda a história pretérita do Estado no Brasil. Ainda cabe notar que esta tabela cobre apenas até o ano de 1975 e que, 
pelo menos até 1979, o Estado Autoritário ainda possuía muitos graus de liberdade. Martins (1997) menciona um estudo feito em 1976 com empresas públicas e empresas estatais onde essas empresas totalizam 231 estando espalhadas por todos os setores da economia quer no setor produtivo quer na prestação de serviços públicos.

\section{Tabela: Períodos de Criação das Empresas Estatais Federais Existentes em 1975}

\begin{tabular}{|c|c|}
\hline Ano & Empresas \\
\hline 1808 & 1 \\
\hline 1860 & 1 \\
\hline $1937-1945$ & 12 \\
\hline $1946-1949$ & 0 \\
\hline 1950.1953 & 9 \\
\hline $1954-1955$ & 0 \\
\hline $1956-1960$ & 8 \\
\hline 1961 & 3 \\
\hline 1964 & 5 \\
\hline $1965-1966$ & 7 \\
\hline $1967-1969$ & 34 \\
\hline $1970-1973$ & 74 \\
\hline $1974-1975$ & 15 \\
\hline Total & 173 \\
\hline
\end{tabular}

Dados não disponíveis 44

Total

217

Fonte: Araújo, Braz J. - As empresas estatais federais:

Listagem e Classificação. São Paulo. 1975. 215 p. Mimeo.

A criação desse número gigantesco de empresas estatais justificavase pela proposta do Estado Burocrático-Autoritário que repousava no combate ao populismo que impregnava o Estado deslocado pelo movimento militar-civil de 1964. Assim, para os novos detentores do poder parece que não havia como salvar aquele estado mas sim praticamente construir ou- 
tro. "O Decreto-lei 200 impôs, de modo unilateral, a ativação de uma nova administração pública através não só de "expedientes" paralelos (como nos anos 50), mas também da montagem de verdadeiras estruturas paralelas (empresas estatais, fundações, autarquias), a partir das quais se imaginava possível compensar as defasagens da administração direta" (Nogueira: 1996: 13). Nesse processo de "desdemocratização", ou seja retirada da sociedade civil de qualquer possibilidade de participação e controle do processo político, as decisões seriam tomadas por uma burocracia que se suponha altamente qualificada. Essa burocracia, ou tecnoburocracia, seria proveniente tanto das Forças Armadas como do próprio Estado e de empresas privadas (O'Donnell: 1975; Bresser Pereira: 1984) mas, paradoxalmente, não corresponde à idéia teórica exata da burocracia pois, ao estar abrigada em empresas da administração indireta, estaria fora dos controles e dos procedimentos que caracterizam a estrutura burocrática convencional.

A "fraca institucionalização" do Decreto-lei 200 trouxe "um número razoável de consequências negativas para a organização interna do Estado": 1) um relacionamento difícil, uma "espécie de tensão permanente" entre as duas esferas (direta e indireta) da administração pública (Martins: 1997: 24); 2) uma disparidade crescente entre a administração indireta e a direta devido ao status diferente de seus quadros (salários, capacitação, capacidade de tomar decisões, etc). Consequência disto, enquanto o setor paraestatal se desenvolvia, os serviços a cargo da administração direta continuavam um processo de deterioração (Martins: 1997). Passaram a coexistir ou a se justapor, dentro do Estado, "não apenas duas esferas públicas, mas também dois tipos de servidores sociologicamente diferentes". De um lado, "o burocrata mal pago, de baixa qualificação, de visão estreita e desmotivado da administração direta; de outro lado, socialmente ascendente o executivo público do setor paraestatal, muitas vezes mais competente, Resourceful, com uma cultura gerencial quando não tipicamente empresarial" (Martins: 1997: 26).

Como acontece em situações não democráticas, "o governo autoritário perdeu o controle sobre essa expansão" (Martins: 1997: 22) das empresas estatais. Weber colocava a necessidade de um forte poder legislativo no sentido de controle da burocracia que poderia vir a constituir um poder burocrático (Held et al: 1983). Na situação de Estado de exceção tínhamos não só um legislativo fragilizado pelo regime, incapaz portanto de exercer 
qualquer controle sobre a burocracia, como um Estado que, apesar de forte, autoritário e centralizado, não conseguia controlar suas próprias crias. Isto abre caminho para algumas observações adicionais. $O$ regime militar instalado em 1964 possuía, como suas motivações básicas, a extirpação da ameaça do comunismo, a moralização da vida pública e, de mais longo prazo, a transformação do País em uma potência à nível mundial. Além do pressuposto básico de descolamento da sociedade civil o novo regime descola-se também da administração pública direta para empreender seu esforço desenvolvimentista. Renega-se a administração direta marcada pela pecha da ineficiência e dos vícios do processo histórico brasileiro e alargase amplamente a administração indireta sob o argumento de que o esforço desenvolvimentista e a pressa para fazê-lo careciam de estruturas ágeis, desamarradas, desimpedidas. Configura-se, como em momentos anteriores, a idéia de dois mundos polares: um seria conspurcado, eivado de interesses clientelistas, populistas, um mundo que, apesar de toda introdução de esquemas modernizadores não teria conseguido vencer opatrimonialismo; de outro lado, um mundo ágil, eficiente, marcado pelo desimpedimento e, principalmente, livre dos vícios históricos da sociedade brasileira. Em outras palavras, esta concepção estaria marcada pela idéia de que o mundo da administração indireta seria impermeável às características estruturais da sociedade brasileira onde ela, administração indireta, está também inserida. Mais especificamente, este Estado paralelo estaria isento da ação de interesses clientelistas, populistas, enfim, do patrimonialismo. A confirmar esta hipótese, estaria sendo assumido que seria possível construir uma realidade "pura" a partir de uma mesma matriz "impura". Esta hipótese não se confirmou, pior que isto. "A supressão ou obstrução, pelo regime autoritário, dos canais institucionais de representação de interesses, com a autonomia adquirida por alguns órgãos governamentais, fez surgir novas formas de articulação e relacionamento entre a burocracia pública e os interesses privados" fazendo "surgir um tráfego novo e incontrolável entre os interesses públicos e privados - indo muito além dos limites das práticas convencionais de lobby, e assentando os fundamentos do que mais tarde assumiria a forma de corrupção generalizada nos altos escalões do aparelho do Estado" (Martins: 1997: 27). Assim, o patrimonialismo irradiase também pelos setores da administração indireta e, possivelmente, com uma voracidade maior do que na direta, dado o volume de recursos e decisões estratégicas manipuladas por aquela esfera de governo. 


\section{A Reforma de Estado na (Nova) Redemocratização}

Assim como nos anos 30 , os anos 80 assistem a necessidade de uma nova configuração do Estado frente à mudanças significativas na economia, mais especificamente, nos sistemas produtivos e no capital financeiro. No caso dos países desenvolvidos a questão se colocava em termos do esgotamento do Estado de Bem-Estar Social, enquanto que no caso dos países periféricos ou emergentes o esgotamento era do chamado Estado Desenvolvimentista. Se, no primeiro caso, o Estado crescia em funções e aparelhos para atender as demandas sociais, no segundo caso, o crescimento justificava-se pela necessidade do Estado alavancar o crescimento econômico dada a fragilidade das burguesias nacionais e a frágil poupança privada. Seja num caso seja no outro, parece haver se estabelecido um consenso de que o remédio recomendado estava na redução do Estado, de seu papel, de suas funções, quer seja no ideário neo-liberal mais feroz, quer não. A constatação da necessidade de um novo ordenamento para o Estado não resulta de um diagnóstico preventivo de uma situação, mas da presença de uma crise que se generalizava por vários países. A crise era da economia mas também uma crise do Estado, levando à consciência de que para se enfrentar a primeira obrigatoriamente haveria de se enfrentar a segunda. Apenas um Estado remodelado, eficiente, seria capaz de enfrentar e debelar a crise econômica.

No caso brasileiro, esta crise se expressa não só pela interrupção do crescimento econômico, ou seja, o desenvolvimentismo não conseguia mais assegurar sua eficiência, mas também a presença de uma inflação elevada que corroía o tecido econômico e social. Esta crise desponta no último governo do período autoritário mas estoura firmemente no primeiro governo da redemocratização. Vale dizer que esta foi extremamente limitada, confirmando o traço histórico da realidade brasileira de incorporar elementos estruturais do velho regime no novo. Assim é que não ocorre uma transição por "ruptura" mas uma transição "transada" (O'Donnell: 1988), incorporando estruturas do regime "derrubado". Em outras palavras, carregam-se os velhos móveis para a nova casa, uma outra versão do conhecido "novos rótulos em velhas garrafas", ou seja, a Nova República guarda traços estruturais do regime autoritário. Assim, não é surpresa que "a busca de maior eficácia e rapidez na administração da crise foi recorrentemente 
Reforma do Aparelho do Estado: Limites do Gerencialismo frente ao Patrimonialismo

interpretada mediante o recurso ao estilo tecnocrático de gestão e ao enclausuramento burocrático das decisões, reforçando a centralização regulatória do Estado e acentuando o divórcio entre o Executivo e o sistema de representação" (Diniz: 1997: 21).

O governo Sarney pode ser caracterizado como o primeiro governo que enfrenta a crise em condições da retomada dos parâmetros democráticos. Estando a crise presente e cada vez mais aguda na vida nacional, o seu combate assumiu prioridade na agenda governamental eclipsando qualquer preocupação com a reforma do Estado e do seu aparelho administrativo. O parcial retorno à democracia no entanto não foi capaz de alterar comportamentos historicamente estabelecidos e este posicionamento avançou pelo governo Collor. É assim que "entre os anos 80 e início dos 90 , as equipes técnicas dos vários ministros responsáveis pelos sucessivos programas de estabilização econômica gozaram de alto grau de insularidade burocrática, não se observando, em nenhum dos casos, obstrução significativa derivada da dinâmica parlamentar" (Diniz: 1997: 29). Ou seja, "o centro do processo decisório continua deslocado para o Executivo com a exclusão da instância parlamentar-partidária" (Diniz: 1997: 31). Em outras palavras, não se forma o que Weber clamava por um forte poder parlamentar para contrabalançar o poder burocrático. E aqui já começa a se esboçar uma das nossas conclusões, qual seja, que a reforma do aparelho do Estado não se situa nele primordial e exclusivamente. Mais importante é reforçar o que controla a estrutura burocrática ou o que venha a substituí-la ou complementá-la. Conforme coloca Diniz (1997: 43): "é preciso que se fortaleçam os partidos e o poder congressual".

Se, pelas razöes expostas, a reforma do Estado e de seus aparelhos administrativos não fez parte do governo Sarney, no governo Collor, com seu ímpeto em ser "moderno", "contemporâneo", o tema entrou na agenda. E entrou numa política de atacado. De novo a necessidade de enfrentar a inflação, com o país à beira de um estágio hiper-inflacionário, direcionou os esforços governamentais para o enfrentamento deste problema. Mas também a questão da reforma administrativa entrou na pauta só que sem um "projeto compreensivo", faltando à reforma "não só uma concepção substantiva refinada, mas também um cálculo estratégico". Assim é que "medidas foram tomadas simetricamente, atingindo indistintamente o setor público, sem considerar as condições efetivas de funcionamento dos órgãos 
governamentais, seus papéis e seus distintos graus de eficiência" (Azevedo \& Andrade: 1997: 65). Além de uma concepção equivocada, a reforma collorista também padeceu de uma "implementação desastrosa" levando ao "desmantelamento da máquina pública federal", fechando órgãos responsáveis por atividades governamentais relevantes (Azevedo \& Andrade: 1997). Em suma, "o governo Collor foi especialmente destrutivo, pela desorganização imposta às estruturas do governo federal (...) e pela desmoralização ainda maior da burocracia pública, quer através de ataques verbais indiscriminados, quer pela demissão arbitrária e inócua de servidores" (Martins: 1997: 29).

As reações, judiciais inclusive, causadas ao projeto de reforma de Collor e seu próprio impeachment retiraram a reforma do aparelho do Estado do centro das preocupaçōes durante o governo Itamar Franco mas sendo a questão tratada "com mais sensibilidade, em abordagem de estilo incremental e segmentado" (Azevedo \& Andrade: 1997: 66). Mas é no governo Fernando Henrique Cardoso que a reforma da administração pública adquire foros de importância, passando a ser "uma questão nacional", com a transformação da Secretaria da Administração Federal, que geria o serviço público, em Ministério da Administração Federal e Reforma do Estado (MARE), isto quer dizer, a reforma do Estado não só entra na pauta governamental como ganha um ministério para conduzí-la. (Bresser Pereira: 1997).

\section{A Reforma Bresser Pereira: o enfoque gerencialista}

A fundamentação da proposta do governo Cardoso, feita pelo seu ministro do MARE Bresser Pereira procura situar a questão da reforma do aparelho do Estado no conjunto mais amplo das atividades e do papel do Estado na sociedade. Ele começa argumentando que os países altamente endividados promoveram o ajuste estrutural (ajuste fiscal, liberalização do comércio, privatização e desregulamentação), o que alcançou resultados positivos ao controlar a balança de pagamentos e as taxas de inflação. Este ajuste não foi capaz, no entanto, de retomar o crescimento econômico. Associado à este ajuste estava a implantação de um Estado mínimo dentro dos parâmetros do ideário neo-liberal, idéia tida como "irrealista" dado que "os cidadãos continuam a exigir mais do Estado", e que as políticas 
públicas desempenham um papel tão grande no capitalismo contemporâneo que o mercado não tem condições de fazer (Bresser Pereira: 1997: 7).

Assim, "a causa básica da grande crise dos anos 80 " tem sido "uma crise do Estado" e esta assume três formas: uma crise fiscal, uma crise das estratégias de intervenção estatal e uma crise da forma burocrática do Estado, o que leva a necessidade, constatado o irrealismo do Estado mínimo, a reformar este Estado (Bresser Pereira: 1997). Além das reformas que envolvem as privatizações e o ajuste fiscal, "igualmente importante é a reforma administrativa que torne o serviço público coerente com o capitalismo contemporâneo" (Bresser Pereira: 1997: 8). E existe uma crescente consciência de que "a administração pública burocrática não corresponde às demandas que a sociedade civil apresenta aos governos por ela eleitos, no capitalismo democrático contemporâneo" (Bresser Pereira: 1997: 8). Em situações onde a administração pública é ineficiente e onde o mercado não faz uma alocação de recursos satisfatória, a necessidade de uma administração pública eficiente passa a ser "um valor estratégico", e a administração pública burocrática deve ser substituída por uma administração pública gerencial (Bresser Pereira: 1997).

O aparecimento da administração pública burocrática (doravante APB) representa um "grande progresso" em relação à administração patrimonialista característica do Estado pré-capitalista, mas estaria esgotada no século XX quando o Estado teve que ampliar o seu papel social e econômico (Bresser Pereira: 1997: 10). Em seu lugar apareceu a administração pública gerencial (doravante APG) que toma emprestado os avanços ocorridos na administração empresarial mas sem perder sua característica específica: "a de ser uma administração que não está orientada para o lucro, mas para o atendimento do interesse público" (Bresser Pereira: 1997: 11). Se esta é a situação nos países mais avançados, nos "países em desenvolvimento", para Bresser Pereira (1997: 11) "a situação era muito pior" configurando-se uma situação em que patrimonialismo, expresso por nepotismo e corrupção, convivia com uma burocracia "beneficiária de privilégios" e marcada por "excesso de quadros", certamente resultado da política patrimonialista. No Estado desenvolvimentista, típico da situação brasileira dos anos 30 aos 80 , "a administração burocrática era uma forma de apropriação dos excedentes por uma nova classe média de burocratas e tecnoburocratas" onde "o excedente produzido pela economia foi dividido 
entre os capitalistas e os burocratas que, além dos mecanismos de mercado, usaram o controle político do Estado para enriquecimento próprio" (Bresser Pereira: 1997: 12).

Se o diagnóstico até agora oferecido é impecável, a proposiçăo tem alguns problemas de concepção, de partido e que certamente repercutem na sua operacionalização. Enquanto a APB concentra-se no controle, nos procedimentos legais para todas as suas ações, não sendo sensível a eficiência, a APG "orienta-se para resultados". A APG, embora entenda que se deva combater a corrupção e o nepotismo, isto não precisa ser feito através de "procedimentos rígidos". "Podem ter sido necessários quando dominavam os valores patrimonialistas; mas não o são hoje, quando já existe uma rejeição universal a que se confundam os patrimônios público e privado" (Bresser Pereira: 1997: 13). Aqui parece residir o pressuposto equivocado do argumento que pode comprometer a proposta. Com toda a carga patrimonialista ainda presente na sociedade brasileira, fica difícil aceitar essa "rejeição universal" aos valores patrimonialistas. Mesmo que exista essa rejeição em amplos setores precisaria extirpar esses valores retrógrados e anti-sociais do patrimonialismo, diga-se dos "patrimonialistas" . Ora, essa é uma tarefa política não administrativa ou resultado de um ato governamental. $O$ que tem se assistido é uma impressionante resiliência do patrimonialismo, capaz de absorver mudanças modernizantes na sociedade brasileira e de se amoldar à nova situação. Talvez pudéssemos pensar em um patrimonialismo camaleônico que consegue não só sobreviver como, ao que parece, se reforçar, mesmo sofrendo a ordem econômica mudanças modernizantes apreciáveis. Talvez o ponto esteja exatamente no fato de que muda a ordem econômica mas não muda a ordem política, pelo menos substancialmente. Quem gere a ordem econômica é fundamentalmente a mesma ordem política. Assim, a burocracia pode ser weberianizada até um ponto que não atrapalhe os interesses patrimonialistas fortemente enraizados e instalados, assim também o capitalismo no Brasil não poderia ser também suficientemente "weberianizado".

Poder-se-ia argumentar se não seria pessimista este pressuposto da existência ainda de valores patrimonialistas na sociedade brasileira. Vamos nos valer do próprio Bresser Pereira (1989) quando em passado nada distante, fazendo uma avaliação de sua passagem pelo Ministério da Fazenda em 1987, assinala que quando deixa o governo com outros "políticos de- 
Reforma do Aparelho do Estado: Limites do Gerencialismo frente ao Patrimonialismo

mocráticos e modernos", "retornam a ele os políticos autoritários e clientelistas, que, mais do que conservadores, são representantes do capital mercantil e parasitário que ainda existe no país" (Bresser Pereira: 1989: 101). Em sua análise, o governo Sarney a partir daí, segundo semestre de 1987, apoia-se no "fisiologismo de uma elite política retrógrada" baseada numa "prática política ultrapassada, clientelista ou fisiológica e, em última análise, corrupta" (Bresser Pereira: 1989: 101). Em um texto que exala um desânimo compreensivo, Bresser Pereira comenta que "por uma ironia do destino a visão de Caio Prado Jr. dos anos sessenta se confirma nos anos oitenta: estamos de volta ao capital mercantil. O capital mercantil, que dominou o Brasil durante séculos, volta ao poder, reassume o comando político e econômico do país". No entanto conclui com palavras de esperança: "este retrocesso, porém, não tem base na realidade econômicá e social do país. É um fenômeno político fora do tempo. É a história repetindo-se como farsa" (Bresser Pereira: 1989: 93).

Ora, todos essas características são traços do patrimonialismo. Mas, mesmo assim, poderíamos argumentar que essa era uma situação típica de - uma transição "transada", mas que o processo de redemocratização avançando pela - finalmente - eleição direta iria nos conduzir ao extermínio de todas as nossas mazelas, ou pelo menos, as principais delas. E foi assim que elegemos .... Collor. E com este governo o patrimonialismo não só não foi extinto ou amenizado, deslocado historicamente, como, muito pelo contrário, se fortaleceu imensamente constituindo-se, talvez, o maior assalto patrimonialista ao Estado Brasileiro em toda sua historia e já nos anos 90. Mas, mesmo assim, e mantendo o otimismo, poderíamos argumentar que 0 impeachment nos purgou. Assim é que a eleição de Fernando Henrique Cardoso traz a possibilidade de finalmente chegarmos ao mundo contemporâneo dada toda sua trajetória pessoal e o partido a que pertencia e o que este representava. Só que, no entanto, para viabilizar sua candidatura, eleição e governo é feita uma aliança, profunda e continuamente respeitada, justamente com aquelas forças que Bresser Pereira aponta que deram sustentação ao governo Sarney em sua "fase mercantil", consubstanciado no chamado "Centrão". Ou seja, o presente é marcado pela sobrevivência, no mínimo, das estruturas e dos interesses patrimonialistas. Ainda assim, poderia ser argumentado que seria necessária esta aliança no sentido de empreender as reformas necessárias de modernização do Estado e da economia. 
Neste caso, estaríamos frente a uma situação paradoxal de contar com os interesses patrimonialistas para acabar com o patrimonialismo.

Vamos recorrer ainda ao próprio Bresser Pereira para atualizar o diagnóstico e a percepção do patrimonialismo na situação brasileira. Bresser Pereira (1996) detecta, após a Constituição de 1988, a "sobrevivência do patrimonialismo e do enrijecimento burocrático, muitas vezes perversamente misturados" afetando a qualidade e custo da administração pública brasileira. Em sua visão, a Constituição de 1988 permitiu que privilégios fossem criados ou consolidados, o que seria "um tributo pago ao patrimonialismo ainda presente na sociedade brasileira" (Bresser Pereira:1996:15). Ainda comentando a transição democrática, Bresser Pereira registra que as forças democráticas que a fizeram foram levadas a celebrar uma aliança política com "o velho patrimonialismo, sempre pronto a se renovar para não mudar" (Bresser Pereira: 1996:15).

Bresser Pereira prossegue sua proposição e defesa da APG ao comentar o esforço consistente de análise da administração pública brasileira feita pelo governo Itamar Franco através de um estudo realizado pelo CEDEC para a ENAP. Em síntese, a discordância fundamental de Bresser Pereira (1996) a este documento repousa no fato dos analistas entenderem que o mal maior a ser atacado localizava-se no "intenso e generalizado patrimonialismo no sistema político", assestando suas críticas ao passado patrimonialista e propondo a reafirmação de valores burocráticos clássicos. A esta proposição, rebate com a necessidade de "uma modernização radical da administração pública - modernização que só uma perspectiva gerencial poderá proporcionar" (Bresser Pereira:1996:18). Ao analisar a questão da estabilidade dos funcionários observa que esta era justificável "enquanto o patrimonialismo era dominante" mas não se mantém quando "o patrimonialismo perde força, deixa de ser um valor para ser uma mera prática"(Bresser Pereira: 1996:20).

Analisando essas colocaçōes, podemos identificar uma contradição na fundamentação de Bresser Pereria, pois, para ele próprio, o patrimonialismo tem voltado (se alguma vez foi embora) com muita força e frequência apenas para citar os últimos anos: foi assim em 1988/89 no governo Sarney (apontado pelo próprio Bresser), na Constituição de 1988, no governo Collor. Assim, não pode-se esperar que o patrimonialismo tenha desaparecido ou esvaecido de uma hora para outra. Concordamos 
Reforma do Aparelho do Estado: Limites do Gerencialismo frente ao Patrimonialismo

com Bresser Pereira quando afirma que o patrimonialismo não é mais dominante, mas não quando estabelece que perde força, deixa de ser um valor. Bresser Pereira (1996:31) volta a este ponto: "tenho dito que a cultura patrimonialista já não existe no Brasil, porque só existe como prática, não como valor. Esta afirmação, entretanto, é imprecisa, já que as práticas fazem também parte da cultura. $O$ patrimonialismo, presente hoje sob a forma de clientelismo ou de fisiologismo, continua a existir no país, embora sempre condenado". O próprio autor reconhece, então, que o patrimonialismo continua a existir e propõe que não basta condená-lo, mas puní-lo. Novamente, não se vêem muitas ações nesse sentido. Todos esses elementos levam-nos a identificar que o patriomonialismo continua não só vivo, presente, mas muito atuante nos processos políticos no Brasil de hoje. Mesmo na ausência de maior fundamentação teórica e analítica vale destacar que, em vários momentos, ações do governo Cardoso recendem ao mais puro patrimonialismo.

A nova concepção de setor público baseia-se numa percepção de que os valores apontados por Weber para defender a estrutura burocrática estariam superados, esgotados frente à nova dinâmica da vida econômica mundial. Os valores apontados por Weber e largamente conhecidos deveriam ser superados por outros tais como "eficiência, competição, qualidade e custo buscados fundamentalmente na administração pública americana (Azevedo \& Andrade: 1997). O referencial weberiano é substituído por um outro osborniano/gaebleriano. Na busca de uma concepção de um Estado eficiente "alguns dos aspectos sociais e políticos que condicionam o funcionamento da burocracia pública, isto é, seu caráter clientelista e patrimonialista, são percebidos como "deformações" ou "desvios", a serem sumariamente suprimidos, antes que fenomenos que expressam formas de adaptação do Estado à complexa realidade econômico-social" (Azevedo \& Andrade: 1997: 73). Em outras palavras, o patrimonialismo está mais vivo e intenso do que pensam os pressupostos da reforma da administração pública.

Frente a estas ponderações, nossa preocupação toma o seguinte rumo: a incorporação de um ethos gerencialista ao Estado pode realmente ser entendido como um avanço em relação à formas existentes de organização da administração pública. No entanto, frente ao exposto, entendemos esse caminho como marcado por elevados riscos. Já introduzimos a colocação de Nogueira (1996) sobre a existência de um Estado constituído por duas 
camadas, uma racional-legal e outra patrimonialista, que formam um macrocefálica bifrontalidade. Entendemos que, na forma proposta, há uma tendência a se constituir uma macrocefálica trifrontalidade onde se agrega agora uma camada "gerencialista". Os riscos são dessa nova camada também se contaminar pelo vírus patrimonialista, assim como esse contaminou as estruturas e os mecanismos paralelos criados em momentos diversos de nossa história recente. O que se supunha, ou se esperava, é que esse Estado paralelo ficasse ou fosse imune a esse vírus e ele acabou sendo contaminado e, em alguns casos, com a criatura superando o criador. Teríamos então convivendo uma estrutura burocrática, possivelmente em acelerado processo de decadência (e com ela os serviços sob sua responsabilidade), uma estrutura patrimonialista que está muito mais implícita, disfarçada do que explícita e é muito maior do que os otimistas acreditam, e uma estrutura gerencialista, que seria a nova "menina dos olhos" do Estado. Frente à esta trifrontalidade e à resistência do patrimonialismo é possível acreditar que o gerencialismo tenha êxito? Qual a capacidade de resistência do gerencialismo ao patrimonialismo? Ainda um outro aspecto já destacado: a capacidade impressio. nante do "velho" se imiscuir no "novo". A história do Estado no Brasil é uma história de acumulação de fenônemos onde não ocorre ruptura, onde o novo se amolda ao velho e, dialeticamente, o velho se amolda ao novo. Se não acontece ruptura no plano político: $1822,1889,1930$, 1945, 1964 (com reservas), 1985, como esperar que a burocracia não siga o mesmo padrão? Por último, questiona-se a viabilidade de êxito de uma reforma que deixa intocada estruturas estratégicas da vida política do país e que são fundamentais para o tipo de administração pública que temos. Assim, a reforma da administração "tornou-se inseparável de uma reforma do Estado, pois depende de uma profunda revisão das funções e práticas estatais, das instituiçōes políticas e das relações Estado-sociedade civil, cujo padrão histórico é perverso e de baixa qualidade" (Nogueira: 1996: 22). Em outras palavras, a questão da reforma administrativa é muito mais ampla, "tornou-se eminentemente política, dizendo respeito à democracia, à refundação de pactos e consensos societais, à participação da cidadania, à valorização das instituições representativas, e não apenas à mera racionalização administrativa" (Nogueira: 1996: 22). 
Para Martins (1997) a reforma das estruturas do Estado só pode ocorrer quando pudermos resolver três questões: 1) que tipo de Estado queremos; 2) que burocracia melhor se adapta a este; 3) que coalizão política apoia a reforma, e relembra que deve ser levado em consideração na hora de deflagrar uma proposta "a cultura política clientelista ainda dominante". E parte para uma conclusão mais radical: "a reforma da administração pública no Brasil exige uma reforma da nova Constituição" (Martins: 1997: 34). Em outras palavras, a reforma do aparelho do Estado está fundamentalmente ligada a um projeto para o país onde muitas instituições estratégicas estão tão carcomidas e ultrapassadas quanto a estrutura administrativa do Estado brasileiro e necessitam de reformas tão urgentes quanto aquela. Não promover estas reformas é deixar o gerencialismo, uma boa idéia, ser presa fácil dos interesses patrimonialistas.

\section{Conclusão}

A análise aqui empreendida levanta uma série importante de questões. Por um lado, as indicações são que as verdadeiras reformas estruturais, que tocam nas questões estratégicas, não são priorizadas. Por outro lado, pensando apenas em termos da reforma do aparelho do Estado, é imprescindível perguntar: constatada a existência, permanência do patrimonialismo, é possível implantar o gerencialismo fazendo tábula rasa do patrimonialismo? É possível a convivência do gerencialismo com o patrimonialismo esperando-se que o primeiro possa superar todos os problemas e dar as respostas efetivas que estaria dando no primeiro mundo? Duas possíveis respostas podem ser oferecidas. Uma repousa em toda a argumentação acima desenvolvida. A outra, em benefício da dúvida, coloca que a implantação do gerencialismo estaria concorrendo para o desaparecimento, ou progressivo enfraquecimento, do patrimonialismo, e, assim, então, seria positivo, mesmo convivendo com o patrimonialismo. Esta possibilidade apenas o tempo - necessário à implantação e consolidação de uma base gerencialista expressiva - e o desenvolvimento de novas pesquisas é que poderão indicar sua viabilidade. 
${ }^{1}$ Este artigo é uma versão modificada do trabalho "Patrimonialismo, Burocracia e Gerencialismo: Um "mix"Possível?, apresentado no Seminário Internacional "Reestruturação e Reforma do Estado: O Brasil e a América Latina no Processo de Globalização". FEA/USP. São Paulo. Maio 1998

\section{Referências Bibliográficas}

ARAÚJO, B.J. de , 1977: Intervenção econômica do Estado e democracia. In: Estado e Capitalismo no Brasil. Carlos Estevam Martins (org.). São Paulo. Hucitec.

AZEVEDO, S. de \& Andrade, L.A. G. de, 1997: A reforma do Estado e a questão federalista: reflexões sobre a proposta Bresser Pereira. In: Reforma do Estado e democracia no Brasil: dilemas e perspectivas. Eli Diniz e Sérgio de Azevedo (org.). Brasília. Editora Universidade de Brasília.

BRESSER Pereira, L.C. , 1984: Development and Crisis in Brazil: 19301983. London. Westview Press.

, 1989: A Crise da "Nova República". Novos Estudos 23. São Paulo. CEBRAP.

, 1996: Da administração pública burocrática à gerencial. Revista do Serviço Público. N. 1 (jan-abr). Vol. 120. Brasília. ENAP.

, 1997: Estratégia e estrutura para um novo Estado. Revista do Serviço Público. N. 1 (jan/abr/1997). Brasília. ENAP.

DINIZ, E., 1997: Governabilidade, democracia e reforma do Estado: os desafios da construção de uma nova ordem no Brasil dos anos 90. In: Reforma do Estado e democracia no Brasil: dilemas e perspectivas. Eli Diniz e Sérgio de Azevedo (org.). Brasília. Editora Universidade de Brasília.

FAORO, R., 1987: Os Donos do Poder - Formação do patronato político brasileiro. 7.a ed. Rio de Janeiro. Globo.

HELD, D. Et al, 1983: Introduction: Central Perspectives on the modern state. In: States \& Societes. David Held et al (ed). The Open University. Oxford. Basil Blackwell Ltd. 
MARTINS, L., 1997; Reforma da Administração Pública e cultura política no Brasil: uma visão geral. Cadernos ENAP. N. 8. Brasília. ENAP. NOGUEIRA, M.A., 1996: A crise da gestão pública: do reformismo quantitativo a um caminho qualitativo de reforma do Estado. Cadernos FUNDAP 21. São Paulo. FUNDAP.

O'DONNELL, G. , 1975: Reflexiones sobre las tendencias generales de cambio en el Estado Burocratico-Autoritario. In: Revista Paraguaya de Sociologia. N.33.

, 1988: Transições, continuidades e alguns paradoxos. In: A Democracia no Brasil - dilemas e perspectivas. Fábio Wanderely Reis e Guillermo O’Donnell (org.). Vértice. São Paulo. 